Resumo

\title{
O efeito da ingestão de carboidratos na glicemia sanguínea de militares, durante a realização de uma marcha de $4 \mathrm{~km}$
}

Wilson de Assis Lacerda Junior Bsci, Laércio Camilo Rodrigues BSci

Introdução: Uma nutrição adequada para as necessidades energéticas e de nutrientes pode auxiliar para um bom desempenho de militares em situação de operações militares. Sendo assim, os horários de consumo de alimentos antes do início de exercícios militares tem grande influência. Por isso, é de relevância considerável conscientizar os militares para o melhor horário de consumo de suas refeições.

Objetivo: Identificar o melhor momento para o consumo de carboidratos, por intermédio da raçāo operacional disponível na rede de suprimento do Exército, antes do início de uma marcha, através da análise da variação glicêmica dos indivíduos avaliados.

Métodos: Participaram do estudo 18 homens saudáveis $(21,9 \pm 3,0$ anos), militares, todos integrantes da brigada paraquedista, realizando o curso de formação de cabo e com relativa experiência em marchas. Foram divididos em 2 grupos: o $1^{10}$ grupo consumiu o café da manhā da raçāo operacional 15 minutos antes de seu início; o 2o grupo consumiu a mesma refeição 45 minutos antes do início da mesma atividade. Realizou-se uma marcha de $4 \mathrm{~km}$, em uma pista de atletismo, sendo que na chegada de cada quilômetro, era realizada a coleta do índice glicêmico, em um intervalo de 10 minutos. Todos estavam com o fardo de bagagem e o fardo de combate. Houve a análise da variação glicêmica em cada quilômetro do mesmo grupo e a diferença entre os grupos a comparação foi feita utilizando testes $t$ de Student, para amostras não-pareadas. Efeitos substanciais foram considerados quando grandes magnitudes de diferença $\mathrm{p}<0,05$ foram observados.

Resultados: Houve diferença significativa durante o $1^{\mathrm{o}} \mathrm{km}$ de marcha e o $3^{\circ} \mathrm{km}$ $(p<0,01)$. Contudo, entre os quilômetros 2 e 4 além nāo houve diferença significativa $(\mathrm{p}>0,05)$.

Conclusão: Houve diferença significativa entre os diferentes grupos no $1^{\circ} \mathrm{km}$ e no $3^{\circ} \mathrm{km}$ em relação ao índice glicêmico. 